\title{
The Functionality of Four Temperaments and Communication Theories towards the Realisation of Peaceful General Elections in Kenya
}

\author{
Benard Odoyo Okal \\ Maseno University, Department of Kiswahili \& other African Languages, Faculty of Arts \& \\ Social Sciences, P.O. Box 333, MASENO \\ Email: benardodoyo@yahoo.com \\ Beverlyne Asiko Ambuyo \\ Maseno University, Department of Kiswahili \& other African Languages, Faculty of Arts \& \\ Social Sciences, P.O. Box 333, MASENO \\ Email: bevily2005@yahoo.com \\ Deborah Nanyama Amukowa \\ Maseno University, Department of Kiswahili \& other African Languages, Faculty of Arts \& \\ Social Sciences, P.O. Box 333, MASENO \\ Email: dnanyama@yahoo.com
}

Accepted: May 17, 2012 Published: June 27, 2012

Doi:10.5296/jsr.v3i1.2012ＵRL: http://dx.doi.org/10.5296/jsr.v3i1.2012

\begin{abstract}
The paper focuses on the general analysis and functionality of both the four temperaments and communication theories in an attempt to comprehend the process, nature and reality of politics, campaigns and general elections in Kenya. Temperaments theory classifies human personalities into four major categories: sanguine, choleric, melancholic and phlegmatic. The paper proposes to highlight how having clear knowledge of these personalities in the political contexts may help the general public in electing peacemakers. The paper also puts into focus how aspects of communication theory especially speech event and speech act theories may be used in understanding our political scenes. The speech event has been used to summarize the nature of politics in Kenya while speech act theory shows how political utterances can be misjudged by the audience hence fuelling untold violence, hate and even mass action. May be psychologists and discourse experts can play a key role in describing personalities, temperaments of the leaders and analyze their utterances in order to realize peaceful general elections in Kenya that can be emulated by other African leaders in the East African community. Remember, a peaceful country is very important for any citizen towards realization of its goals so as to uplift the social, political and economic sectors. However, a
\end{abstract}


country cannot have peaceful atmosphere if the populace seems to be divided into ethnic lines, jobs given through nepotism and general national developments lopsided. It is a common phenomenon in Kenya that before, during and after general elections, violence generally occurs. Is it temperaments of the leaders or their utterances during campaigns that contribute to violence?

\section{Introduction}

The paper focuses on the application of two major theories: Four temperaments theory and Communication theory towards the realization of peaceful elections in Kenya. The work is divided into two sections. The first section deals with the concept of Four Temperaments theory, chronological analysis of its origin and developments in various scenarios such as the field of religion, human resources developments and how it can be used in the political arena for the realization of peaceful general elections in Kenya.

The second section captures the application of the elements of communication theory in a more technical way by referring to its broad aspects especially the speech event and speech act. The speech event theory is concerned with how we use speeches in different contexts by dwelling on the following essential elements of consideration: settings, participants, ends/goals, acts/activities, key, instruments, norms, genre and topics. We have looked at the manifestations of these elements when speeches are made during campaigns for the general elections. The other concern of this section is the applicability of speech act theory in the realization of peaceful general elections in Kenya. According to this theory, it is evident that any utterance we make normally has forces that are categorized as locutionary, illocutionary and perlocutionary. These forces have great effects on the listeners. Furthermore, the illocutionary forces are normally assigned functions such as: directives, commissives, representatives, verdictives, and declaratives and even expressive. These theories are also superimposed with the Gricean norms in conversation: quantity, quality, clarity and manner.

\subsection{The Concept of Four Temperaments Theory}

The term temperament comes from a Latin word known as 'Temperamentum' that means proper mixing, and the idea behind it was that if the human body fluids were reduced in their intensity by balancing the humors with each other, then healing would occur (Media Spotlight, 1994). From this Latin word the theory was born. However, the Four Temperaments theory is referred to as a way devised especially by the psychologists so as to comprehend the human characteristics or nature, assisting in improving the human condition and also grouping people into various personality characteristics that seemingly appear to make up their basic temperaments (Martin \& Bobgan, 1992). The so called temperament means the characteristic phenomena of an individual's emotional nature while personality is a sum total of the physical, mental, emotional and social characteristics of an individual. Temperaments are inborn traits while personality is shaped by nature and nurture.

1.1.1 The Origin and Chronological Analysis of Four Temperaments Theory

Temperaments theory is claimed to may have originated from the Ancient Egypt or Mesopotamia but was later developed as a medical theory by a great Greek physician Hippocrates (460-377 BC) (Martin \& Bobgan, 1992). However, the concerns about human 
personality and temperaments that culminated into the birth of the Four Temperaments theory seemingly could be traced right from the following scholars arranged chronologically as Empedocles, Hippocrates, Plato, Aristotle and Galen (Media Spotlight, 1994).

From the ancient times, there were myths and occult practices, physicians and philosophers who used the four humors of body fluids (blood, yellow bile, black bile and phlegm), four temperaments and also the signs of zodiac so as to treat ailments and hence assist in comprehending the human differences. Zodiac is the imaginary area especially in the sky in which the sun, moon and other planets appear to lie, and which has been divided into twelve equal parts each with a special name and symbol (Oxford Advanced Learner's Dictionary, 2010). The four temperaments had links with the twelve signs of zodiac in the field of astrology (the study of the positions of the stars and the movements of the planets in the belief that they influence human affairs) (OALD, 2010). These links heralded the following classifications whereby blood had links with (Gemini, Libra and Aquarius), yellow bile with (Aries, Leo and Sagittarius), black bile with (Taurus, Virgo and Capricorn) and phlegm with (Cancer, Scorpio and Pisces) (Media Spotlight, 1994).

According to a great Greek philosopher known as Empedocles (495-425 BC), the four primary elements that were used to describe the human temperaments were: fire (that could be warm and dry), air (that could be warm and moist), earth (that could be dry and cold) and also water (that could be moist and cold). Furthermore, during the Empedocles time, each element seemingly was assigned a corresponding god and goddess because cosmology was mixed together with mythology. The god and goddess assigned to these elements were: Zeus (the fire), Hera (the air), Aidoneus (the earth) and Nestis (the water).

The other great philosopher who came after Empedocles was Hippocrates (460-377BC) who developed and seemingly expanded the former's evaluation on human personality and temperaments by using four corresponding body fluids sometimes called humors: blood, yellow bile, black bile and phlegm. According to Hippocrates, the human health depends on the proper balancing of these four humors and there is a relationship between the body fluids and the yearly seasons. For example, phlegm increased during winter and reduced during summer. Hippocrates therefore came up with the following schema giving corresponding names from the elements of Empedocles as here below: blood had links with spring, yellow bile with Summer, black bile with Autumn and phlegm with Winter (Media Spotlight, 1994).

After Hippocrates, came Plato (427-347 BC) who claimed that humors really had a great contribution into ones behavior. For example, madness of a person was as a result of morbid humors contacting a person's mortal soul. He later concluded that 'the truth is that the intemperance of love is a disease of the soul due chiefly to the moisture and fluidity which is produced in one of the elements by loose consistency of the bones' (Media Spotlight, 1994 p. 2). On the other hand, Plato made very interesting remarks regarding bad behavior that:

'For no man is voluntarily bad; but the bad became bad by reason of an ill disposition of the body and bad education, things which are hateful to every man and happens to him against his will. For where the acid and briny phlegm and other bitter and bilious humors wander about in the body, and find no exit or escape, but are pent up within and mingle their own vapors with the motions of the soul, and are blended... and being carried 
to the three places of the soul... they create infinite varieties of ill-temper and melancholy, of rashness and cowardice, and also forgetfulness and stupidity' (Media Spotlight, 1994, p. 2).

Aristotle (384-322 BC) who was a student of Plato, also embraced the explanations of other great gurus who studied the personality and temperaments of humans. He argued that the shape of the body to some extent reflected the activities of the soul as well and he associated warm and thick blood with strength, and cold and thin blood with intelligence.

Though Empedocles used four elements of fire, air, earth and water to describe human personality and temperaments, on the other hand Hippocrates, Plato and even Aristotle looked at the body fluids to categorize some human behaviors. In the later years the theory was then developed by Claudius Galen from Pergamum (131-200 AD) who though recognized the humors or body fluids in order to categorize human personalities and temperaments, also looked into the physiological reasons as the main cause of such human behaviors, moods and emotions. The scholar categorized these behaviors as hot and cold, dry and wet. These were later developed into four temperaments technically referred to as sanguine, phlegmatic, choleric and melancholic.

The scholar concluded that if you are a sanguine in which you are influenced by blood then you become cheerful, hearty, outgoing, sturdy/strong, fearless, optimistic and interested in physical pleasures. If you are phlegmatic then you are influenced by phlegm (thick white material that we cough when we have cold) then you become cold, aloof, unemotional, uninvolved, dependable and a trifle dull. If you are choleric then you produce yellow bile from the liver hence you exhibit traits such as anger, hate and have fits of temper (giving in to most bad impulses). If you are described as melancholic then you are driven by a worse black bile from liver hence you are always depressed, unhappy and suicidal.

1.1.2 Developments and Application of the Four Temperaments Theory

From the works of the early scholars, it is very evident that human personalities and temperaments depend upon the body fluids or humors hence the following classifications arose: sanguine, phlegmatic, choleric and melancholic. However, the character traits of these kinds of temperaments have been discussed and given traits differently so as to suit different placements and professions. For example, according to Martin and Bobgan (1992) the following traits can be observed on each category of temperaments such as: Sanguine [cheerful, friendly, talkative, lively, restless, self-centered and undependable], Phlegmatic [calm, dependable, efficient, easy-going, passive, stubborn and lazy], Choleric [optimistic, active, confident, strong-willed, quick to anger, aggressive and inconsiderate] and Melancholic [melancholic/sad, sensitive, analytical, perfectionist, unsociable, moody and rigid].

On the other hand, other scholars define these temperaments in some other ways such that the sanguine is considered to be [fairly extrovert, enjoy social gathering, making new friends, tends to be boisterous, quite creative, often day dream, some alone time is crucial for them, very sensitive, compassionate and thoughtful] but with the following weaknesses [chronically late, tend to be forgetful, a little sarcastic, lose interest quickly when pursuing a new hobby, very much people persons, talkative and shy, and often emotional]. The phlegmatic has the following traits [tend to be self content and kind, very accepting and affectionate, very 
receptive and shy, prefer stability to uncertainty and change, very consistent, relaxed, calm, relational, curious, observant, are good administrators, can be very passive and aggressive].

The choleric is [ a doer, have a lot of ambition, energy and passion and always try to instil it to others, can dominate people of other temperaments especially the phlegmatic, many great charismatic military and political figures are choleric] and the weakness is that [they like to be leaders in charge of everything and can also be manipulative]. The melancholic have traits such as [a thoughtful ponderer, very considerate and get rather worried when they could not be on time of events, can be highly creative in activities such as poetry and art, can be occupied with the tragedy and cruelty in the world, often a perfectionist, often self reliant and independent] but with a weakness that [they can get so much involved in what they are doing and forget to think of others].

The Four Temperaments theory has been used in various circumstances. When discussing Four Temperaments, astrology and personality testing, Martin and Bobgan (1992) realised that the theory had also a great impact on the lives of Christians. These two scholars claimed that Christians believed that they could understand themselves better and the others in the society by relying on personality characteristics. In this regard the Christians therefore could be able to analyse their strengths and weaknesses, discover how God can use their gifts, improve their relationships with others and also get a head with their careers.

The theory became so popular to the Christians because people could therefore understand themselves and the others, look for solutions to solve differences arising amongst them, helps in knowing strengths and weaknesses and look for solutions, and can be used to understand why one acts in a certain sinful behaviour because of temperaments. The theory can also help in making an appropriate judgement about ourselves. It enhances communication amongst people so that necessary ways can be improvised to relate with others. It assists in one self improvement and satisfaction so as to replace weaknesses with strengths and hence enhance identity and behaviour. Christians also believed that the theory is compatible with the scripture because we dwell in a psychologised society.

When writing the report on 'The Next Big Thing' in Temperament theory, Barens (2006) realised that the theory has a great impact in the development of human resource. Being the founder of Interstrength Associates (ISA) that is a corporate training company formed to serve organizations that intend to maximize individual and company results, the author applied this theory so as to describe core values, motivations and needs of individuals and hence translating these into practical business applications in the company concerned. Many corporate bodies apply this theory in enhancing leadership development, motivation of employee, retention to creativity and innovation to navigate change. The scholar has applied the theory in the corporate world basing the argument in the following three core ideas: to be active, describe a contribution to the organization and also get to the talent as well. In this regard, Barens (2006) renamed the common nomenclature of Four Temperaments theory into the theorists, stabilizers, improvisers and the catalysts. These names have been highly accepted by workers of various corporate bodies.

1.1.3 The Four Temperaments Theory and Politics

The four temperaments theory seemingly has also an impact in the political arena. In the year 2004, Wellington Nyongesa of The Sunday Standard newspaper wrote a very interesting 
article on the magazine called society that talked about 'Personality: Why you behave the way you do'. In this article, the author consulted so widely from the psychological intelligentsia and realized the applicability of the Four Temperaments theory in the analysis of our political leaders. In deed this article was instrumental to us but seemingly the scholars did not give it more weight in the realization of peaceful elections in Kenya as we are trying to unravel in this discourse.

When consulting Dr Fred Owiti who is a Nairobi based psychiatrist, Nyongesa (2004) gathered that personality is traditionally divided into two major categories: extrovert (outward persons) and introvert (internal persons). It is interesting that those who are led are categorized as introverts and the leaders as extroverts who are generally considered as talkers, assertive and respond to matters quickly. The psychiatrist therefore concluded that the politicians, evangelists and preachers normally fall very well in this category of the extroverts. These two broad categorizations of personalities of extroverts and introverts can therefore be subdivided into various four temperaments as had been talked about earlier in this paper such that sanguine could be termed as high level extrovert while choleric is a low level extrovert. On the other hand, melancholic has low level of introversion and phlegmatic has a high level of introversion.

In the Kenya's political scene, Nyongesa (2004) was informed that we can be able to observe the traits of our politicians even in the public domains. But the question we may ask is: Who is a better leader who can in fact bring peace to the nation? This is a technical question because the Four Temperaments theory has not been a factor in making choices for our leaders whether president, members of parliament and even the civic leaders. We believe that even if we don't categorically say so and so can be a good leader, we believe an exposition of this theory to a wider Kenya's populace can help in making concrete and democratic decisions in electing worthwhile and peaceful leaders.

When referring to Dr Tim Lahaye's report on identifying and understanding strengths and weaknesses of temperaments, Nyongesa (2004) recorded that: A sanguine who is a super extrovert has the following strengths [talkative, compassionate, responsive, warm and friendly, enthusiastic and outgoing] but has the weaknesses such as [emotionally unstable, egocentric, undisciplined, exaggerates and unreliable]. The choleric who is a low level extrovert has the following strengths [visionary, leader, strong willed, independent and decisive] but has weaknesses such as [cold and unemotional, sarcastic, domineering, angry and cruel]. The phlegmatic who is regarded as high level or super introvert has strengths such as [cool and calm, diplomatic, dependable, humorous and reliable] but has weaknesses such as [sedentary/working while spending a lot of time sitting down and not moving, stingy, worrier, fearful and procrastinator/one who delays in doing something that he or she should do]. The melancholic who is a low level introvert has these positive traits [gifted, analytical powers, industrious, aesthetic and self sacrificing] but has these weaknesses [moods, negative, revengeful, persecution-prone, self-centred, self disciplined and unsociable].

While we believe we may not have the moral probity to make proper decisions on who should become a good leader, we believe we can give an intellectual incitement to make you think, make the right choice and elect a visionary and dependable leader. If the theory is inculcated in the minds of Kenyans and other citizens in Africa, then we believe we may 
stand a better chance of electing good leaders hence enjoy peace and stability before, during and after elections. In supporting this theory, Sunday Standard (2004) in the editorial of Society Magazine titled 'Understanding people's temperaments can make the world a better place' sums up the functionality of Four Temperaments theory that:

'Everywhere, there are expectations for people to behave in a certain way - even when it goes against their temperaments. Although no one can be placed in the box and said to belong to one personality, having a good understanding of who we are and who others are can help us to achieve greater success and understanding in our lives. It takes all sorts of people to make a world, and the sooner we realize that, the better off everyone will be. By realizing that human beings are different, both in their genetic make-up and upbringing, we can begin to support each other to bring out the best in each person. For example, if we know that a certain temperament is inclined towards leading while another towards following, all we need to do is to put the necessary structures in place. Ensure that the ones with an inclination to lead get the opportunity to do so, and the followers also are left to do what they will do best'. (p. 3).

It is very clear from the excerpt that having knowledge of the Four Temperaments theory can indeed reorganize our political scenes in Kenya and hence help us in electing good leaders.

\subsection{Communication Theory}

There are numerous explanations and approaches towards the definition of the communication theory. However, it is clear that every communication depends on the speaker/sender, message, medium for communication and the receiver or the listener. In many instances, humans seem to be communicating through speaking more in our day to day interactions than writing. Even though speaking is a very important skill in language teaching and use, it is very difficult to teach an individual because of the phonetic complexity involved. In fact through speaking one conveys information to the people and also serves as an identity marker. It is a skill that if not trained well and properly regulated in communication can cause a disaster and hatred amongst the different ethnic communities in a given social set up.

In this section, we look at some two aspects of communication theory that are generally evident in discourse analysis as a discipline. These are the: speech event theory and speech act theory. The paper shows how these two can be used in analyzing the nature of politics and the speeches made by our politicians whom we believe could help in enhancing peaceful elections in Kenya.

\subsubsection{Speech Event Theory and Realization of Peaceful Elections in Kenya}

Speech event theory was propounded in 1972 by an American sociologist known as Dell Hymes (Hubbard, 2000). The sociologist defined the theory as the activities that are generally governed by rules or norms for the use of speech. Speech events include general conversation, speeches in churches, classrooms and can also be witnessed in the political arena. Dell Hymes realized that any speech event relies on the following nine elements such as: setting, participants, ends, acts, key, instrumentality, norms, genre, and topic.

Setting simply draws our attention to the physical environment of the speech event. In Kenya, political speeches are generally spoken in the market places, along the streets, social places, sports stadia, churches, market places and in very few instances these speeches are 
made in the halls. The participants during the political campaigns are generally politicians who are contenders of various elective positions and political party supporters of varied ages combining both the males and females.

The main ends or goals of the participants are to propagate the party's blueprint, convince the supporters and also to parade to the supporters the contenders. In many instances in Kenya, political speeches are made so as to paint the wrong way other political parties that are considered as opponents. Acts of the political speech event are the clarifications of the party policies, criticisms of the opposing political parties and also dispensing hate speeches so as to belittle the other parties. There is also dancing to the famous political songs and other secular songs. Besides dancing, there are ululations, praising of the speakers and hurling insults against opponents.

When talking about key of the speech event in the Kenya's political scenario, we generally refer to the register whether formal or informal language is used. In many instances, political campaigns are characterized by informal language use whereby grammars of either Kiswahili or English are distorted. The main concern of the speakers is to convey the message and never bothered by the strict rules of the languages concerned. Some speakers even go to the extent of speaking in mother tongues so as to drive the point home, disrespecting others and also vary their tones when speaking.

Instrumentality as an element of speech event theory refers to the medium or channel used by the participants. In many cases during political campaigns speaking as an instrument normally overrides writing. Speaking is normally performed by the political class while listening makes the better portion of the followers. The writing as a medium is seen on the placards that carry very funny messages for example, 'so and so tosha!, Nyanza is ODM, Central is PNU, Rift Valley is UDM and any other discourses that seemingly tend to show solidarity and great support to the party. Other instruments include clubs, spears, other weaponry and scary traditional paraphernalia.

The element of norms shows the behavior of the participants that generally accompany language in speeches. Our politicians use microphones and loud speakers so as to be heard very well. Some forms of turn taking when giving speeches are observed. Many speeches are normally made in order whereby the main speaker speaks last when other party supporters and contenders had spoken. There is also code mixing and code switching whereby both Kiswahili and English, and other vernacular languages are used. The element of topic of course dwells on politics. It is generally known amongst our politicians that politics is a game and in fact a dirty one. Therefore, what is normally talked about in political arenas focuses on politics, imaginary developmental plans, empty promises, ideas and general political party structures.

Regarding the genre of the speech event, generally, politicians use many stylistic devices so as to drive the point home. There is usage of satire (using humour to show faults or weaknesses of the others), metaphors (describing something in a way different from its normal use), poems and even songs are also used. This element of genre tends to be a darling of many politicians in that whenever they make speeches, a bigger proportion is covered by these devices.

You could hear the use of riddles concerning ball playing, others referred to as thieves, 
monkeys and even the uncircumcised. Many political campaigns use songs. Since political parties comprise different tribes from different regions, corresponding songs are normally played when inviting a politician from a given region to make his or her speech. If the speaker is from Luo Nyanza then the famous 'ohangla' or 'benga' songs that seem to be political in content are played. The trend is followed when other speakers from may be Rift Valley, Western, Nairobi, Central, Eastern, Coast and any other region represented in the political campaigns.

Music or songs seemingly have a big impact in our political arena in that it invites the listeners and or party supporters very fast to their meeting points. However, it has been observed that music expresses emotions and the listeners generally agree on the type of emotions that are expressed in a musical piece. Scherer and Zentner (2001) concludes that music produces emotional effects in the listeners that even go beyond the cognitive inference of what the music can be said to express. It is evident therefore that the intentions of songs evoke emotions more than the intentions of the musical piece itself. This can be injurious to the electioneering processes if not well checked. May be the message that is expressed in such songs are in fact a greater factor for incitement. We must therefore try to be very careful with our songs during political campaigns.

If we want to have very peaceful elections in Kenya and even any other African nations then the speech event theory should have the same nine elements but crafted in a way that peace prevails. For example, the setting should be arranged in a good conference hall, participants be calm politicians and their supporters, and also ensure that the ends or general goals are for the good of all citizens and to sale political parties policies in a good way. It will also be prudent to ensure that the words we utter whether when questioning, criticizing or clarifying something should show mature acts. In regards to the key of this theory, speakers should ensure that they respect others, vary their tone in language and speaking and writing as medium of the speech event instrument are generally organized. The speaking norms should be checked, the genre especially musical pieces preaching peace should at all cost be embraced. Lastly, the topics to be discussed during campaigns should be directly illuminating the salient features of the political parties' blueprints.

\subsubsection{Speech Act Theory and the Realization of Peaceful Elections in Kenya}

Another aspect of communication theory that can help in the realization of peaceful elections is called speech act theory. Speech act theory was propounded by one philosopher by the name Austin, J. L. who in 1962 wrote "How to do things with words" and later developed by Searle in 1969 (Hatch, 1992). The scholars said that whatever utterances we make in communication, we normally assign functions directly or indirectly to each of them. These speech act functions are considered as very important aspects of speech act theory that clearly indicates that people use language to do things and when using language then performative verbs are applied giving rise to some forces. Austin confirms that always an utterance comes out with speech forces that are linguistically referred to as locutionary, illocutionary and perlocutionary.

Any well formed utterance by a speaker carries with it a force called locutionary. This means that the speaker has the capability to pronounce words and sentences. This utterance dispensed by the speaker has meaning or intention thus creates an illocutionary force which 
may have many meanings like warning, committing, directing or even giving a verdict. These functions of illocutionary force have been renamed as: directives, commissives, representatives, verdictives, and declaratives and expressive. All these are generally regarded as speech act functions which we believe influence the reactions of the listeners. Remember when we utter words or sentences then we may be directing, committing ourselves, representing, giving a verdict, declaring something or expressing our feelings.

In the Kenya's political scenario we normally hear directives such as [It is our turn we must lead this country this time, how many times are we going to be serving as vice presidents, we have been marginalized for long, we must act now]. Such directives may mean very sinister motives to the concerned citizens. Politicians also never tire to dispense commissives whereby they tend to commit themselves to the voter for instance [I will tarmac this road within one hundred days, I will commit my whole salary to the constituency development fund account, I will construct markets in every ward]. All these commissives turn to be illusions. Sometimes representatives that normally represent assertion of truth by using words such as very, almost and even extremely are uttered by the political class for instance [It is extremely hard but I will try my best to change the constitution].

Other political utterances are regarded as verdictive such as [These old people will not get presidency this time, these young and jumpy youths cannot lead, this one comes from a smaller tribe therefore cannot lead]. A declarative utterance in most cases is uttered and at the same time performance is done for example [The province has declared you the sole candidate of PNU in the Mount Kenya region, you are the only leader in Rift Valley, today we make you a Kaya elder]. On the other hand some expressive utterances are made by the politicians. Expressive utterance contains interjections so as to show emotions such as [Oh! My tribesmen! We are finished!].

When the speaker is through with his speech then all his utterances are decoded by the listeners hence causing a reaction that can translate into very active behavioral changes of the listeners. This force is called perlocutionary force. Reactions of the listeners will in fact vary depending on the way he or she understood its meaning. For example, when an utterance such as: 'Oh! My tribesmen! We are finished!', to some extent may mean an incitement to the tribesmen who may decide to take arms and start fighting their neighbors, ensure that they get power through thick and thin and may stir untold animosity amongst the many ethnic groups in the country.

This speech act theory summarizes what our politicians are doing and take us through. As they go round the country in pursuit of voters, the words they utter in essence are decoded by their listeners who in turn tend to make unnecessary reactions. The listeners react because as the speakers make speeches, they watch also the use of paralinguistic devices then get to understand what they mean, their intentions and evoke reactions. These are also coupled with how speakers repeat words or sentences so as to ensure the point is driven home.

It is our deeper conviction that our politicians know very well that when they utter words or sentences, they are aware that they are making a speech that is well formed, has intentions, both surface and deeper meanings and know exactly the perlocutionary effect that shall be evoked on the listeners. Therefore, when one makes any speech during campaigns, then we believe it is intended and the reactions on the part of the audience readily known. In fact we 
don't expect therefore any vocal politician or an activist to cry foul that he is hunted or targeted in this era of freedom of speech. We must beware because words are very dangerous if used unwisely and can reverse the old adage of "actions speak louder than words" to "words speak just as loud as actions".

What can assist in peaceful elections in Kenya is in fact the proper use of the speech act theory and superimposes it with the Gricean cooperative principles of conversation. As reported by Hubbard (2000), Grice wrote in 1975 a very important piece titled 'Logic and Conversation' in which he argued that communication cannot work effectively unless participants generally observe some norms such as: quantity (saying amount of information that is adequate, be brief but don't dispense too much or too little), quality (say what you know to be true and not false), relevance (always say what is relevant to the topic and the situation and never deviate) and lastly consider clarity (avoid obscurity and ambiguity that means always ensure you are clear when dispensing utterances so as to be well understood).

\section{Conclusion}

The papers has shown that it is very instrumental for the general public to understand different individual personalities and temperaments and that of our leaders so that we may know the strengths and weaknesses of a sanguine, phlegmatic, choleric and melancholic leaders. If this knowledge is inculcated into the minds of many Kenyans then probably we may be able to make right choices of leaders hence realize very peaceful elections. Remember that the Four Temperaments theory has been applied successfully in the religious circles and even the developments of human resources in order to boost the company's image. Therefore, it can also be used fruitfully in the political arena. Meanwhile as we dwell on the Temperaments theory, we must also embrace the salient elements of speech event and speech act theories so as to boost the communication strategies before, during and after elections for the realization of peace and stability in the country. This can also be a lesson to other African nations and countries that are persistently marred by political turmoil.

\section{References}

Barrens, L. (2006). The Next Big Thing in Temperament Theory. Retrieved September 13, 2011 from http://www.Prweb.com/pdfdownload/431789.pdf

Hatch, E. (1992). Discourse and Language Education. Cambridge: Cambridge University Press.

Hubbard, H. (2000). Discourse: Language in context. In: V. Webb, \& Kembo-Sure (eds.) African Voices: An Introduction to the Languages and Linguistics of Africa. Southern Africa: Oxford University Press, pp.245-267.

Martin \& Bobgan, D. (1992). Christians and the Four Temperaments Theory. Santa Barbara, California: EastGate Publishers. Retrieved September 13, 2011 from http://www.psychoheresy-aware.org/images/4temp_01.pdf

Media Spotlight (1994). A Biblical Analysis of Religious and Secular Media. Special Report on Four Temperaments, Astrology and Personality Testing. Redmond, WA: Media Spotlight. $\quad$ Retrieved September 13, 2011 from http://www.mediaspotlight.org/pdfs/FOUR TEMPERAMENTS.PDF 
Nyongesa, W. (2004, January 11). Personality: Why you behave the way you do. In: Society Magazine, Sunday Standard. Issue Number 7. Nairobi: The Standard Group Ltd, pp. 5-7.

Scherer, K. R., \& Zentner, M. R. (2001). Emotional Effects of Music: Production rules. In: P. N. Juslin, \& J. A. Sloboda (eds.) Music and Emotion: Theory and research. Oxford: New York: Oxford University Press, pp. 361-392. Retrieved September 20, 2011 from http://psy2.ucsd.edu/ charris/Scherer Zentner.pdf

Sunday Standard (2004, January 11). Editorial of Society Magazine: Understanding people's temperaments can make the world a better place. Issue Number 7. Nairobi: The Standard Group Ltd, p. 3. 